\title{
Chemical Composition, pH Value, and Points of Zero Charge of High Calcium and High Iron Electric Arc Furnace Slag
}

\author{
Siti Zu Nurain Ahmad ${ }^{1}$, Hamdan, R., ${ }^{2, *}$, Wan Afnizan Wan Mohamed ${ }^{2}$, N. Othman ${ }^{2}$, Nur Shaylinda Mohd Zin ${ }^{2}$ \\ ${ }^{I}$ Department of Engineering Technology, Faculty of Engineering Technology, \\ Universiti Tun Hussein Onn Malaysia, 86400 Parit Raja, Batu Pahat, Johor, MALAYSIA. \\ ${ }^{2}$ Department of Water and Environmental Engineering, Faculty of Civil and Environmental Engineering, \\ Universiti Tun Hussein Onn Malaysia, 86400 Parit Raja, Batu Pahat, Johor, MALAYSIA \\ *Corresponding author E-mail:rafidahh@uthm.edu.my
}

\begin{abstract}
Electric arc furnace (EAF) slag as filter media has been extensively used nowadays for wastewater treatment technology. Steel slag was produced as byproduct from steelmaking processes. However, different batches of steel slag production produce different composition. Thus, this study determined the chemical composition, $\mathrm{pH}$ value and points of zero charge (PZC) of two different samples of electric arc furnace (EAF) slag; high iron EAF slag (Slag HFe) and high calcium EAF slag (Slag HCa). The steel slag were characterized using Xray Fluorescence Spectroscopy (XRF) analysis for the chemical composition, extraction with boiling water for $\mathrm{pH}$ value, and salt addition method for PZC. Slag HFe was mainly consisted of $38.2 \%$ ferric oxide and $20.4 \%$ calcium oxide, $10.20 \mathrm{pH}$ value and $\mathrm{pH} 10.55$ for PZC. While for Slag HCa, they were composed of $1.64 \%$ ferric oxide and $49.5 \%$ calcium oxide of $\mathrm{pH}$ value of 11.11 and $\mathrm{pH} 11.75 \mathrm{for}$ PZC. Therefore, Slag HCa was considered as a more basic species compared to Slag HFe.
\end{abstract}

Keywords: electric arc furnace slag; pH; chemical composition; points of zero charge; characterization

\section{Introduction}

The by-product of the steel refining processes and steel production in the industry is known as steel slag [1]. Nowadays, steel slag have been significantly used in wider fields of application, for instance, as aggregates for road construction, as armor-stones for hydraulic engineering construction as well as fertilizer in agriculture [2]. Moreover, steel slag is utilized in wastewater treatment technology as separated filter media to remove certain heavy metals, ammonium nitrogen, phosphorus and phenol [3]. Also, steel slag which has been used as filter media in constructed wetlands is demonstrated as a bright solution for the removal of phosphorus which follows the mechanism of adsorption and precipitation [4].

Commonly, the slags are named from the type of furnaces they are produced [1]. During the production of steel, the iron ores, scrap metals, and fluxing agents are heated more than their melting points in which they produced the metal in fusion and liquid; and another layer was produced on the surface of the melts. The surface layer formed was called slag. The four most regular slag produced as by-product in the steel making industry are blast furnace slag (from iron making in a blast furnace), basic oxygen furnace slag (from extensive iron refining in basic oxygen furnace), electric arc furnace slag (recycled scrap melted in electric arc furnace) and melter slag (produced due to iron sand is changed to melter iron) [5].

Physically, steel slag shows both geometrically and chemically heterogeneous surface [1]. Steel slag is known to have different sizes and shapes of pores, pits, vacancies and steps. On the other hand, steel slag is considered to possess a chemical heterogeneity due to the different functional groups obtained at the steel slag's surface together with many different surface contaminants. Nevertheless, both these physical and chemical heterogeneities have significant contribution to the adsorption property of steel slag [5]. Besides that, steel slag can also be recycled and directly handled because of its non-hazardous nature. Teo et al. [7] performed a leaching test of EAF slag before and the results showed that, the concentration of heavy metals such as $\mathrm{Pb}, \mathrm{Cd}, \mathrm{Cr}, \mathrm{Zn}, \mathrm{Cu}$, and $\mathrm{Mn}$ that leached out from the steel slag still can be accepted within the standard limit issued by the Department of Environmental Malaysia.

Generally, steel slag has a $\mathrm{pH}$ value in between $\mathrm{pH}$ 8-10, therefore they are considered as alkaline. Also, as mentioned by National Slag Association, steel slag can have a $\mathrm{pH}$ value of more than $\mathrm{pH}$ 12 , which were mainly contributed by very high amount of free calcium oxide $(\mathrm{CaO})$ compound in the steel slag. Previously, Ning et al. [8] also obtained a very high alkaline $\mathrm{pH}$ value of steel slag, which was at $\mathrm{pH} 11.99$

On the other hand, the points of zero charge (PZC) is the $\mathrm{pH}$ value when the surface of the substances have net neutral charge. In terms of adsorption chemistry, at PZC, the surface of the adsorbent has net electrical neutrality; in which the acidic or basic functional groups do not influence the $\mathrm{pH}$ of the solution [9]. Therefore, when the $\mathrm{pH}$ of the solution increases and higher than PZC, thus the charge of surface of filter media will be directed to more negative as compared to before due to the increase in $\mathrm{OH}^{-}$in the system. Therefore, adsorption of negative species were hindered and less efficient due to repulsion between the same species. On the contrary, when the $\mathrm{pH}$ of the surface is less than the PZC, this indicated that there are more positive charges on the surface of the 
filter media. Thus, this results in a higher efficiency for adsorption of negative species.

Meanwhile, steel slag is mainly made up of metal oxides such as $\mathrm{Fe}_{2} \mathrm{O}_{3}, \mathrm{CaO}, \mathrm{Al}_{2} \mathrm{O}_{3}$ and $\mathrm{MgO}$ [10]. However, the composition of different metal oxides might a little bit varies because of random sources/places of the slag's origin. Note that, metal oxides as well as metal hydroxides have significant contribution in the adsorption of negatively charged species in the aquatic systems [11]. Nevertheless, the physicochemical character of steel slags were affected by the different sources due to different feedstock ores, fluxes and manufacturing process. Therefore, it is crucial to characterize the different properties of steel slag in order to obtain the best steel slag desired for any further research to be done utilizing steel slag.

\section{Methodology}

In the present study, two samples of electric arc (EAF) slags; labeled as Slag HFe and Slag HCa were obtained from Antara Steel Mills Sdn. Bhd, Pasir Gudang, Johor. The obtained EAF slag were sorted out and sieved using test sieve shaker, Endecotts Lombard Rd. London, model Sw193BR, England with British Standard sieve BS410/1986. All collected EAF slag were put on top of the screen mesh and were shaken for 10 minutes. The selected EAF slag were of sizes in between $9.5 \mathrm{~mm}$ to $20 \mathrm{~mm}$ which were the optimum sizes obtained from the previous study [12].

Prior to the characterization study, the EAF slag of desired sizes were cleaned up using tap water two times followed by distilled water. After that, the EAF slag were dried up in the oven for 24 hours at $105^{\circ} \mathrm{C}$ [13]. This was done in order to minimize impurities or contaminants on the samples as well as to obtain constant weight of the samples.

The characterization of EAF slag was done by determining the (1) chemical composition using X-ray Fluorescence Spectroscopy (XRF) analysis, (2) pH value using extraction with boiling water, and (3) points of zero charge using salt addition method.

For the analysis of EAF slag using XRF, the samples need to be crushed into desired size which was 63 micrometer. Therefore, the slag were crushed using Aggregate Impact Value (AIV) to be broken down into smallest possible particles. Subsequently, Fritsch ball mill grinder model Pulverisette 6, Germany was used to further ground the steel slag onto finer particles. The setting of the grinding was at $350 \mathrm{rpm}$ of 60 minutes with a 3 minutes pause for every 15 minutes. The apparatus used were thoroughly cleaned using ethanol to reduce contaminations and impurities. Then, the ground samples were sieved through a 63 micrometer test sieve and collected to be ready for analysis [14].

To study the chemical composition of the EAF slag, XRF model Bruker S4 Pioneer was used. The crushed EAF slag powder needed to be shaped into pellet prior to the analysis. Therefore, $8 \mathrm{~g}$ of EAF slag powder was weighed and mixed together with $2 \mathrm{~g}$ of LICO wax. The mixture was stirred manually to maximize its homogeneity. Then, the mixture were pressed using the die press machine at pressure gauge of $15 \times 10^{4} \mathrm{~N}$. After the pellet was formed, it was put inside the desiccator upon analysis.

Meanwhile, to measure the $\mathrm{pH}$ value of the EAF slag, method of extraction with boiling water was used following the European Council of Chemical Manufacturers' Federations (CEFIC), 1986. $4 \mathrm{~g}$ of powdered EAF slag sample was weighed out and put into a $250 \mathrm{ml}$ beaker. $100 \mathrm{ml}$ of distilled water were added into the beaker and boiled on the hot plate for 5 minutes. The beaker was ensured to be covered with a watch glass. After 5 minutes, the beaker was put aside and thermometer was inserted. The solution was allowed to settle for a few moments. Then, before the solution temperature dropped below $60^{\circ} \mathrm{C}$, the supernatant liquid was poured off as soon as possible. After the decanted portion reached room temperature, the $\mathrm{pH}$ of the solution was measured. Noted that the $\mathrm{pH}$ of the extract/solution measured was considered as the $\mathrm{pH}$ value of the EAF slag [15].

Moving on, the point of zero charge (PZC) of the EAF slag was measured following the salt addition method. A few modifications have been done to the primary reference [11] to obtain more reliable results. Three different moralities of inert electrolytes; $0.01 \mathrm{M}$ sodium chloride $(\mathrm{NaCl}), 0.1 \mathrm{M} \mathrm{NaCl}$, and $1 \mathrm{M} \mathrm{NaCl}$ was used to obtain triplicates. Inert electrolytes in this system are; any combination of sodium $(\mathrm{Na})$ or potassium $(\mathrm{K})$ with nitrate, chloride, or perchlorate ions with respect to metal oxides. Sodium chloride was chosen in this study as the inert electrolytes, because $\mathrm{NaCl}$ can produce repeatable results of the same value of PZC despite the different concentration of electrolyte used and the nature. Also, $\mathrm{NaCl}$ shows no specific adsorption of either ion. [16]. Therefore, since EAF slag is mainly composed of metal oxides, thus for the PZC determination of EAF slag, $\mathrm{NaCl}$ is suitable as the inert electrolytes. $50 \mathrm{ml}$ of adjusted $\mathrm{pH}$ of $0.01 \mathrm{M}$ sodium chloride solution was put inside the conical flask. Twelve different $\mathrm{pH}$ of $0.01 \mathrm{M}$ sodium chloride were prepared using adequate amounts of $0.1 \mathrm{M}$ $\mathrm{HCl}$ or $0.1 \mathrm{M} \mathrm{NaOH}$ solution; at $\mathrm{pH} 2,3,4,5,6,7,8,9,10,11,12$ and 13 [16]. To each different $\mathrm{pH}$ solution, $0.5 \mathrm{~g}$ EAF slag was added and then shaken at $170 \mathrm{rpm}$ for 24 hours using shaker model Daiki DK-0S010 Orbital shaker, Korea. The initial and the final pHs of the solutions were measured and recorded. Then, $0.1 \mathrm{M}$ and $1 \mathrm{M}$ sodium chloride as inert electrolytes were used instead of $0.01 \mathrm{M} \mathrm{NaCl}$ and treated similarly as above. To obtain the PZC, the graph of differences between final and initial $\mathrm{pH}(\Delta \mathrm{pH})$ versus the initial $\mathrm{pH}$ were plotted for the three different molarities of inert electrolytes and the $x$-intercept was identified as PZC [11].

\section{Results and Discussion}

\subsection{Chemical Composition of Electric Arc Furnace (EAF) Slag}

The chemical compositions of two different EAF slags were tabulated in Table 1. From there, it could be seen that the chemical composition of EAF slags were primarily consisted of metal oxides. Slag HFe contained the highest amount of ferric oxide $(\mathrm{Fe} 2 \mathrm{O} 3)$ at $38.2 \%$ followed by calcium oxide $(\mathrm{CaO})$ at $20.4 \%$ and silicon dioxide ( $\mathrm{SiO} 2)$ at $15.2 \%$.

On the other hand, for Slag $\mathrm{HCa}$, the highest amount was $\mathrm{CaO}$ (49.5\%), and $\mathrm{SiO} 2$ (18\%). However, the amount of $\mathrm{Fe} 2 \mathrm{O} 3$ was very little, only accounted as $1.64 \%$ of overall composition. The low amount of $\mathrm{Fe} 2 \mathrm{O} 3$ was highly related to the appearance of the steel slag. Slag HFe which was high in iron $(\mathrm{Fe})$ appeared to be dark and black steel slag whereas Slag $\mathrm{HCa}$ which was high in calcium (Ca) but low in $\mathrm{Fe}$ appeared to be as white steel slag. Though they were both electric arc furnace slag, however, since their chemical composition were different, therefore their physical appearance also differ. Also, different functional groups at the surface together with various surface impurities can contribute to the chemical heterogeneity in steel slag [1]. Besides that, different sizes, shapes of pores, pits, vacancies and steps of the EAF slag caused physical heterogeneities thus this also contribute to the distinctive adsorption characteristic of EAF slag [5].

In addition, the third highest amount of oxide, silica group interact differently, as in ionized onto different charges with respect to the $\mathrm{pH}$ of the solution they reacted. To make it clear, at higher $\mathrm{pH}$ values, silica acts as a negatively-charged species, whereas at lower $\mathrm{pH}$ values, silica tend to be a positively-charged species [17]. Besides that, higher percentage of silica has high mechanical strength, good chemical stability, and good adsorbents due to their granular structure [18]. 
Table 1: Chemical composition of EAF slag HFe and EAF slag HCa

\begin{tabular}{|l|c|c|}
\hline \multicolumn{1}{|c|}{ Percentage (\%) } & EAF Slag HFe & EAF slag HCa \\
\hline $\mathrm{Fe}_{2} \mathrm{O}_{3}$ & 38.2 & 1.64 \\
\hline $\mathrm{CaO}$ & 20.4 & 49.5 \\
\hline $\mathrm{SiO}_{2}$ & 15.2 & 18 \\
\hline $\mathrm{Al}_{2} \mathrm{O}_{3}$ & 7.03 & 2.23 \\
$\mathrm{MnO}$ & 5.19 & 0.38 \\
\hline $\mathrm{MgO}$ & 3.22 & 4.32 \\
\hline $\mathrm{C}$ & 1 & 1 \\
\hline $\mathrm{Cr}_{2} \mathrm{O}_{3}$ & 1.6 & 0 \\
\hline $\mathrm{TiO}_{2}$ & 0.54 & 0.22 \\
\hline $\mathrm{BaO}$ & 0.21 & 0 \\
\hline $\mathrm{P}_{2} \mathrm{O}_{5}$ & 0.34 & 0 \\
\hline $\mathrm{SO}_{3}$ & 0.28 & 2.58 \\
\hline
\end{tabular}

\subsection{Ph Value of Electric Arc Furnace (EAF) Slag}

The $\mathrm{pH}$ value of both Slag $\mathrm{HFe}$ and Slag $\mathrm{HCa}$ are tabulated in Table 2. The test was done in triplicate and the average $\mathrm{pH}$ value for Slag $\mathrm{HFe}$ was $\mathrm{pH} 10.20$ meanwhile for Slag $\mathrm{HCa}$ was $\mathrm{pH}$ 11.11. Noted that Slag $\mathrm{HCa}$ had higher $\mathrm{pH}$ value as compared to Slag HFe. The slightly higher $\mathrm{pH}$ value for Slag HCa was directly proportional to the high percentage of calcium oxide in the slag. Calcium oxide is a basic oxide which has very high $\mathrm{pH}$ value. Therefore, similar to Ning et al. [8] which obtained $\mathrm{pH}$ value near to 12 , Slag HCa was considered as extremely basic. On the other hand, $\mathrm{pH}$ value of Slag HFe was considered as lower relative to Slag HCa. This is mainly due to the higher percentage of $\mathrm{Fe}_{2} \mathrm{O}_{3}$ in Slag HFe. It is known that, $\mathrm{Fe}_{2} \mathrm{O}_{3}$ is an amphoteric oxide, so it exhibits both basic and acidic properties thus the $\mathrm{pH}$ value is lower.

Table 2: Average $\mathrm{pH}$ value of Slag $\mathrm{HFe}$ and Slag $\mathrm{HCa}$ from triplicate samples

\begin{tabular}{|c|c|c|}
\hline $\mathrm{pH}$ value & Slag HFe & Slag HCa \\
\hline $\mathrm{pH}$ value 1 & 10.31 & 11.41 \\
\hline $\mathrm{pH}$ value 2 & 10.16 & 10.89 \\
\hline $\mathrm{pH}$ value 3 & 10.14 & 11.04 \\
\hline Average & $10.20 \pm 0.09$ & $11.11 \pm 0.27$ \\
\hline
\end{tabular}

\subsection{Points of Zero Charge (PZC) Of Electric Arc Fur- nace (EAF) Slag}

Point of zero charge is the $\mathrm{pH}$ of the net neutral charge at the surface of the substances. To obtain the PZC, salt addition method was performed. When salt addition method was conducted, there was a reaction between the surface groups of the EAF slag with the $\mathrm{H}^{+}$and $\mathrm{OH}^{-}$ions in the solution during the agitation time. Thus, this caused the $\mathrm{pH}$ value to be shifted accordingly [5]. The graph of Final - Initial $\mathrm{pH}$ versus initial $\mathrm{pH}$ were plotted and the $\mathrm{x}$ intercept was identified as the PZC. The graph of PZC for Slag $\mathrm{HFe}$ and Slag $\mathrm{HCa}$ was as shown in Figure 1 and Figure 2 respectively.

The graph for three different molarities of $\mathrm{NaCl}$ were plotted and the graph seemed to be in a similar shape. Therefore, the $\mathrm{x}$ intercept which determined PZC for EAF slag were also similar. Table 3 shows the PZC for Slag HFe and Slag HCa. The PZC for Slag HFe was averaged at $\mathrm{pH} 10.55 \pm 0.27$ meanwhile for Slag $\mathrm{HCa}$ was at $\mathrm{pH} 11.75 \pm 0.14$. As stated by Kosmulski [16], different molarities of inert electrolytes do not affect the PZC of the surface, thus the PZC for both slags for different molarities of inert electrolytes did not differ much. Mineral dissolution and reprecipitation reactions might cause minor deviation in the graphs of the same set of different molarity due to the surface-charge properties that were changed which occurred during titrations [19].

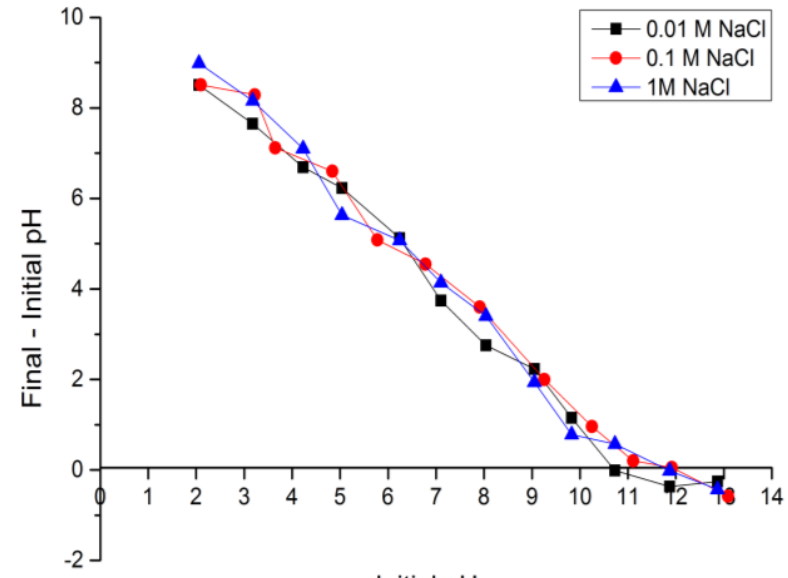

Initial pH

Fig. 1: Average PZC for triplicate samples of Slag HFe

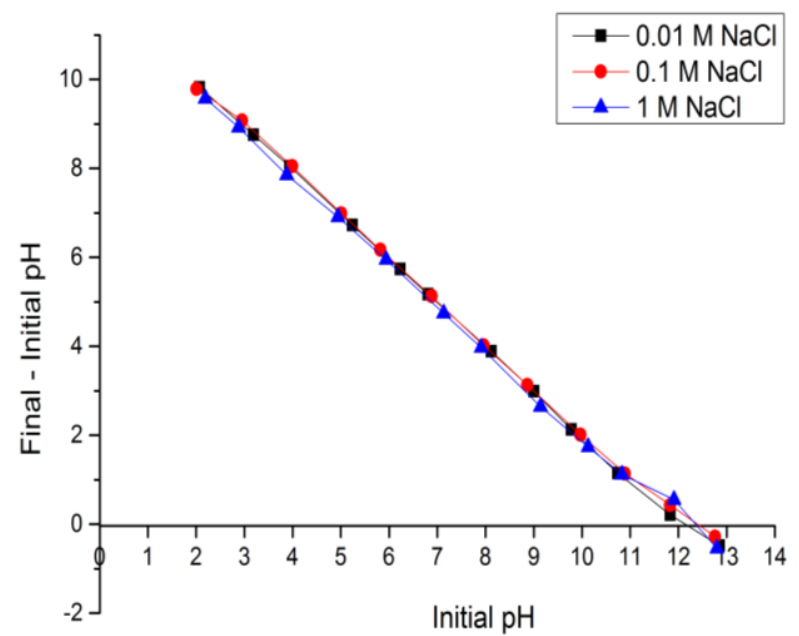

Fig 2: Average PZC for triplicate samples Slag $\mathrm{HCa}$

This average value indicated that, there was no net charge at the surfaces of the slag, at $\mathrm{pH} 10.55$ (for Slag HFe) and $\mathrm{pH} 11.75$ (for Slag $\mathrm{HCa}$ ), the positive and negative are of the same amount, thus this means that the surface of EAF slag were in a neutral state. Therefore, at this $\mathrm{pH}$, there were very little to no adsorption of anions or cations can be found on the surface. Meanwhile, at higher $\mathrm{pH}$ than PZC, anionic species have a low adsorption rate due to the repulsion between species and surface layer (high amount of $\mathrm{OH}-)$ [17]. On the contrary, cationic species have higher tendency to be adsorbed at higher $\mathrm{pH}$ than PZC.

On the other hand, at lower $\mathrm{pH}$ values than $\mathrm{PZC}$, positive charges will dominate the surface and at $\mathrm{pH}$ less than 10.55 and 11.75 for Slag $\mathrm{HFe}$ and Slag $\mathrm{HCa}$ respectively, the adsorption of negative charged species were more effective. Similar concept was applied as in Mushtaq et al. [17], positively charged species will repel because of the same charges.

Therefore, based on the high $\mathrm{pH}$ values and high PZC values of both Slag HFe and Slag HCa, they were considered as basic substances. In addition to that, both slags were majorly composed of metal oxides and it is well known that metal oxides are basic in nature [18]. Also, as a comparison, Slag HCa had higher basicity; higher $\mathrm{pH}$ value and $\mathrm{PZC}$ as compared to Slag HFe. The main difference was due to the high amount of $\mathrm{Fe} 2 \mathrm{O} 3$ in Slag HFe, an amphoteric oxide, which might be the reason for lower $\mathrm{pH}$ and PZC as compared to Slag HCa [19].

Table 3: PZC for Slag $\mathrm{HCa}$ and Slag HFe

\begin{tabular}{|l|l|l|}
\hline \multicolumn{3}{|c|}{ Points of Zero Charge (PZC) } \\
\hline & Slag HFe & Slag HCa \\
\hline $0.01 \mathrm{M} \mathrm{NaCl}$ & 10.25 & 11.85 \\
\hline $0.1 \mathrm{M} \mathrm{NaCl}$ & 10.61 & 11.81 \\
\hline
\end{tabular}




\begin{tabular}{|l|l|l|}
\hline $1 \mathrm{M} \mathrm{NaCl}$ & 10.78 & 11.59 \\
\hline Average & $10.55 \pm 0.27$ & $11.75 \pm 0.14$
\end{tabular}

\section{Conclusion}

Slag HFe was mainly consisted of higher $\mathrm{Fe}$ than $\mathrm{Ca}$ oxides; (38.2\% ferric oxide; $20.4 \%$ calcium oxide), 10.20 of $\mathrm{pH}$ value and PZC of 10.55. Meanwhile, Slag HCa was mainly consisted of higher $\mathrm{Ca}$ than Fe oxides; (1.64\% ferric oxide; $49.5 \%$ calcium oxide) with $\mathrm{pH}$ value of 11.11 and PZC of 11.75. Slag HCa was more basic in nature and had higher PZC compared to Slag HFe.

\section{Acknowledgement}

We are grateful for the fundings provided by Ministry of Higher Education and University Tun Hussein Onn Malaysia; ERGS VOT.E031, FRGS VOT 1613 and GPPS VOT U513.

\section{References}

[1] Yildirim, I. Z., \& Prezzi, M. Chemical, Mineralogical, and Morphological Properties of Steel Slag. Advances in Civil Engineering, (2011), pp. 1-13

[2] Motz, H., \& Geiseler, J. Products of steel slags an opportunity to save natural resources. Waste Management, Vol. 21(3), (2001), pp 285-293.

[3] Yi, H., Xu, G., Cheng, H., Wang, J., Wan, Y., \& Chen, H. An overview of utilization of steel slag. Procedia Environmental Sciences, Vol. 16, (2012), pp. 791-801.

[4] Vymazal, J. Constructed Wetlands for Wastewater Treatment, (2010), pp. 530-549

[5] Pratt, C., Shilton, A., Pratt, S., Haverkamp, R. G., \& Elmetri, I. Effects of redox potential and $\mathrm{pH}$ changes on phosphorus retention by melter slag filters treating wastewater. Environmental Science and Technology, Vol. 41(18), (2007), pp. 6585-6590.

[6] Xue, Y., Hou, H., \& Zhu, S. Characteristics and Mechanisms of Phosphate Adsorption onto Basic Oxygen Furnace Slag. Journal of Hazardous Materials, Vol. 162, (2009), pp. 973-980.

[7] Teo, P., Abu Seman, A., Basu, P., \& Mohd Sharif, N. Characterization of EAF steel slag waste: the potential green resource for ceramic tile production. Procedia Chemistry, Vol. 19, (2016), pp. 842-846.

[8] Ning, D., Liang, Y., Liu, Z., Xiao, J., \& Duan, A. Impacts of steelslag-based silicate fertilizer on soil acidity and silicon availability and metals-immobilization in a paddy soil, PLoS ONE, (2016), pp.1-15.

[9] Ibrahim, M. N. M., Ngah, W. S. W., Norliyana, M. S., Daud, W. R. W., Rafatullah, M., Sulaiman, O., \& Hashim, R. A novel agricultural waste adsorbent for the removal of lead (II) ions from aqueous solutions. Journal of Hazardous Materials, Vol. 182(1-3), (2010), pp. 377-85.

[10] Drizo, A., Forget, C., Chapuis, R. P., \& Comeau, Y. Phosphorus removal by electric arc furnace steel slag and serpentinite. Water Research, Vol. 40(8), (2006), pp. 1547-1554.

[11] Hosseini, S., Choong, T. S. Y., Abdullah, L. C., \& Beh, C. L. Removal of iodide ions from aqueous solution by electric arc furnace slag. Journal of Engineering Science and Technology, (2015), pp. 73-81.

[12] Afnizan, W. M., Hamdan, R., \& Othman, N. Study of the maximum uptake capacity on various sizes of electric arc furnace slag in phosphorus aqueous solutions. In Soft Soil Engineering International Conference 2015 (2015), Volume 136

[13] Barca, C., Gérente, C., Meyer, D., Chazarenc, F., \& Andrès, Y. Phosphate removal from synthetic and real wastewater using steel slags produced in Europe. Water Research, Vol. 46(7), (2012), pp. 2376-2384.

[14] International Atomic Energy Agency (1997). Sampling, Storage and Sample Preparation Procedures for XRay Fluorescence Analysis of Environmental Materials. Vienna: INIS Clearing House.European Council of Chemical Manufacturers' Federations. (1986). Test Methods for Activated Carbon, pp. 39, Brussels: CEFIC.

[15] Kosmulski, M. (2009). Surface Charging and Points of Zero Charge (Volume 145). Boca Raton, Florida: CRC Press.
[16] Mushtaq, M., Tan, I., Ismail, L., Nadeem, M., Sagir, M., Azam, R., \& Hashmet, R. Influence of PZC (Point of Zero Charge) on the static adsorption of anionic surfactants on a Malaysian sandstone. Journal of Dispersion Science and Technology, Vol. 35(3), (2015), pp. 343-349.

[17] Ngah, W. S. W., \& Hanafiah, M. A. K. M. Removal of heavy metal ions from wastewater by chemically modified plant wastes as adsorbents: A review. Bioresource Technology, Vol. 99, (2008), pp. 3935-3948.

[18] Appel, C., Ma, L. Q., \& Rhue, R. D. Point of zero charge determination in soils and minerals via traditional methods and detection of electroacoustic mobility. Geoderma, Vol. 113, (2003), pp. 77-93.

[19] Atkins, P., Overton, T., Rourke, J., Weller, M., \& Armstrong, F. (2010). Inorganic Chemistry. ( $5^{\text {th }}$ Edition). New York: W. H. Freeman and Company. 